\title{
Electrochemical Characterization of Platinum Nanotubules Made via Template Wetting Nanofabrication
}

\author{
Eric Broaddus, ${ }^{1}$ Joel Brubaker, ${ }^{2}$ and Scott A. Gold ${ }^{2}$ \\ ${ }^{1}$ Institute for Micromanufacturing, Louisiana Tech University, Ruston, LA 71272, USA \\ ${ }^{2}$ Chemical and Materials Engineering Department, University of Dayton, Dayton, OH 45469, USA \\ Correspondence should be addressed to Scott A. Gold; sgold1@udayton.edu
}

Received 3 April 2013; Accepted 13 August 2013

Academic Editor: Shen-Ming Chen

Copyright (c) 2013 Eric Broaddus et al. This is an open access article distributed under the Creative Commons Attribution License, which permits unrestricted use, distribution, and reproduction in any medium, provided the original work is properly cited.

\begin{abstract}
Standard oxidation-reduction reactions such as those of ferrocyanide and ferrocene have long been employed in evaluating and comparing new electrode structures with more traditional configurations. A variety of nanostructured carbon electrodes developed in recent years have been reported to exhibit faster electron transfer kinetics than more traditional carbon structures when studied with these redox reactions. This type of comparison has not been widely explored for nanostructured platinum electrodes that have become increasingly common. In this work, a platinum nanotubule array electrode was fabricated via a simple template-based process and evaluated using the standard ferrocyanide redox reaction. The nanotubule array electrodes were observed to more closely approach ideal reversible behavior than a typical Pt black/Nafion fuel cell electrode or a standard polished Pt disc electrode. The apparent heterogeneous electron transfer coefficient was determined using the Nicholson method and found to be one to two orders of magnitude greater for the nanotubule array electrodes, depending on the diameter of the nanotubules, in comparison with these same two more traditional electrode structures.
\end{abstract}

\section{Introduction}

Metal nanowires, rods, tubes, and other so-called "onedimensional nanostructures" [1-3] have drawn increasing attention due to their unique properties. Among the wide variety of methods reported for fabrication of such nanostructures are template-based methods $[2,4-8]$ ), electrospinning [9], deposition onto nanowire or nanofiber supports [10-12], and others [13-15]. One-dimensional carbon and metallic nanostructures have shown promise in electrocatalytic applications, such as in small fuel cells and electrochemical sensors. Beyond their high surface-to-volume ratio, these nanostructures present many potential advantages in electrocatalytic applications, including fewer diffusion impeding interfaces with polymeric binders, more facile pathways for electron transfer, and more effective exposure of active surface sites.

Standard redox reactions such as those of ferrocyanide or ferrocene have long been employed as benchmarks in evaluating various carbon [16] and platinum [17-20] electrode structures, preparation techniques, and surface treatments. While carbon nanotube-based electrodes have been widely evaluated in this manner [21-25], electrochemical studies of platinum nanostructures have focused on organic molecules important to fuel cells (e.g., methanol and formic acid) [3, $8,26]$ or various biosensor applications [1, 27]. Comparison of results for different platinum nanostructures is made challenging by the wide range of testing conditions, though both faster $[3,26]$ and slower $[8]$ electron transfer kinetics in comparison with commercial catalysts have been reported along with enhanced mass transport [8] in nanostructured catalyst layers.

The focus of this work is to examine electron transfer kinetics of the classic ferrocyanide reaction on a platinum nanotubule array electrode fabricated using a simple template wetting process. The ubiquity and long history of this quasireversible, single-electron redox system should enable more meaningful comparison with other electrode structures. The template wetting nanofabrication process used to fabricate the platinum nanotubule array electrodes has been previously demonstrated by Luo et al. [5] The resulting arrays appear similar to those obtained with other template-based processes, though the individual structures are tubular rather than the more common nanowires or rods $[2,6-8,28]$ obtained 
using electrodeposition process. Electron transfer kinetics will be compared to a standard platinum disc electrode as well as an electrode prepared with a commercial platinum blackbased catalyst ink.

\section{Material and Methods}

2.1. Platinum Nanotubule Array Fabrication. A template wetting process, previously demonstrated by Luo et al. [5] and illustrated in Figure 1, was utilized to fabricate platinum nanotubule arrays. This approach makes use of a porous template, in this case commercially available porous alumina membranes (Whatman, Anodisc, $60 \mu \mathrm{m}$ thick, 100 or $200 \mathrm{~nm}$ nominal pore diameters with pore densities of $10^{10}$ and $10^{9}$ pores $/ \mathrm{cm}^{2}$, resp.), to define the geometry of individual nanotubules. The templates were wetted with a precursor solution prepared of platinum (II) 2,4-pentanedionate $\left(\mathrm{Pt}(\mathrm{acac})_{2}\right)$ (Alfa Aesar) and poly(D,L-lactide) (PDLLA) (Sigma-Aldrich) in a 3:1 ratio in chloroform (Acros Organics, ACS Reagent) with a final concentration of $66.6 \mathrm{mg}$ $\mathrm{Pt}(\mathrm{acac})_{2} / \mathrm{mL}$ (Figure $1(\mathrm{a})$ ). The wetted template was allowed to dry in air for $24 \mathrm{hrs}$ leaving a $\mathrm{Pt}(\mathrm{acac})_{2} / \mathrm{PDLLA}$ film coating the pore walls of the template, as shown in Figure 1(b). Sufficient solution was used such that if it is assumed that all $\mathrm{Pt}$ in solution penetrated the template pores to form tubules with a resulting density equivalent to that of bulk platinum and that all pores were uniform and cylindrical, the tubule walls would be $5 \mathrm{~nm}$ thick. This estimate would be conservative as some material was observed on the external surfaces of the template. This however was removed using a helium plasma etch (200 mtorr, for $10 \mathrm{~min}$ ) in a PlasmaTherm RIE system (Figure 1(c)). An annealing step (Figure 1(d)) in air at $200^{\circ} \mathrm{C}$ for $24 \mathrm{hrs}$, followed by $1 \mathrm{hr}$ at $350^{\circ} \mathrm{C}$, followed to reduce the $\mathrm{Pt}(\mathrm{acac})_{2}$ to $\mathrm{Pt}^{0}$ and to oxidize and remove the PDLLA [5]. Finally, the alumina template was partially removed by etching in a $25 \mathrm{wt} \% \mathrm{KOH}(\mathrm{aq})$ for $2 \mathrm{~min}$ followed by a DI water rinse to expose the Pt nanotubes as shown in Figure 1(e). A Hitachi S-4800 field-emission SEM was used to visually inspect the nanotube array.

2.2. Electrode Preparation. The $\mathrm{Pt}$ nanotubule array was attached to a polished glassy carbon electrode (CH Instruments, $3 \mathrm{~mm}$ in Kel-F) using an alcohol-based conductive graphite adhesive (Alfa Aesar product number 42466) to facilitate electrochemical evaluation. Performance of the $\mathrm{Pt}$ nanotubule array was compared to that of a polished polycrystalline platinum disc electrode ( $\mathrm{CH}$ Instruments, $2 \mathrm{~mm}$ in Kel-F) and a platinum black-based electrode prepared using a commercial catalyst (HiSPEC 1000, Alfa Aesar). The Pt blackbased electrode was prepared by pipetting an ink containing Pt black dispersed in DI water and Nafion (5 wt.\%, Solution Technology, Inc.) to a final concentration of $2 \mathrm{mg} \cdot \mathrm{mL}^{-1} \mathrm{Pt}$ with $10 \%$ Nafion by mass, a composition typical of fuel cell electrodes, onto a polished glassy carbon electrode surface and allowing it to dry in air at room temperature for $24 \mathrm{hrs}$ [29-33].

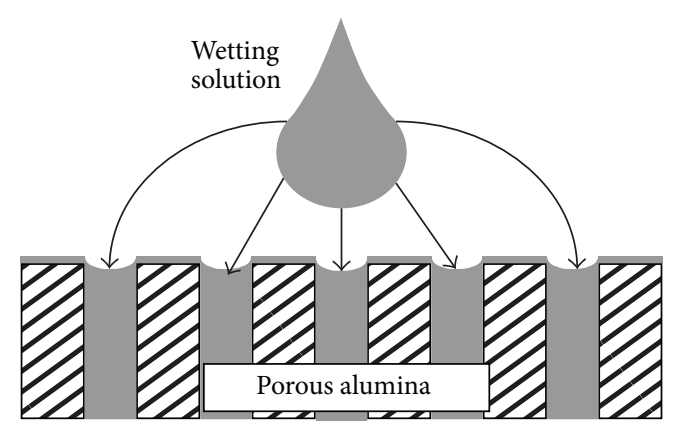

(a)

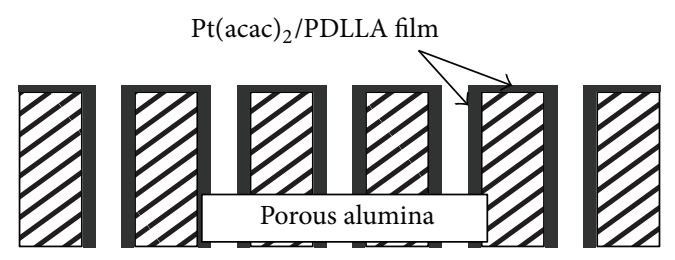

(b)

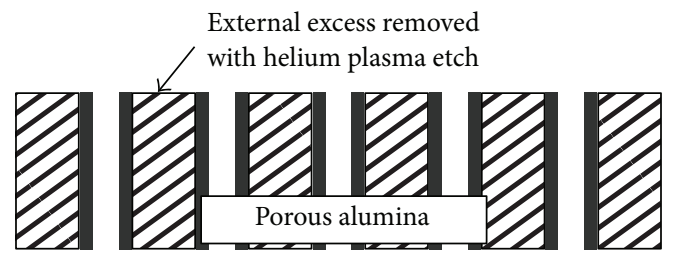

(c)

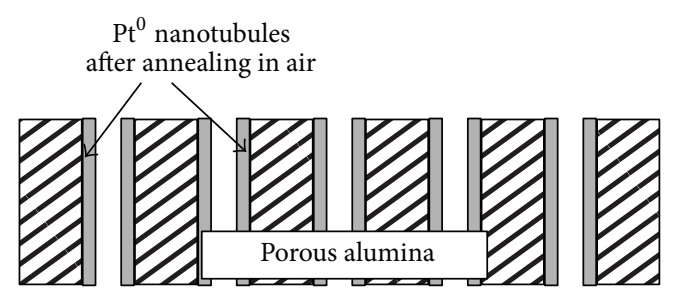

(d)

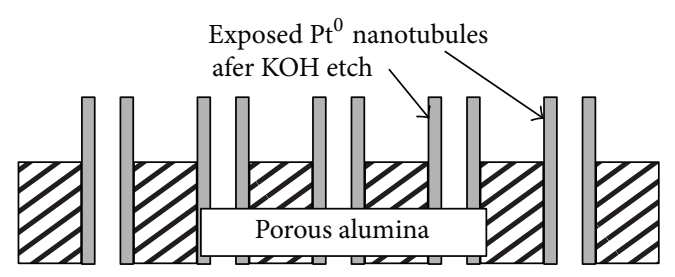

(e)

FIGURE 1: Template wetting nanofabrication of platinum nanotubules. (a) A porous alumina template is wetted with a solution of platinum (II) 2,4-pentanedionate ( $\left.\mathrm{Pt}(\mathrm{acac})_{2}\right)$ and poly(D,L-lactide) (PDLLA) in chloroform. (b) After evaporation of the solvent, a solid $\mathrm{Pt}(\mathrm{acac})_{2} /$ PDLLA film coats template pores. (c) Excess material on the outer surfaces is removed using a helium plasma etch, followed by $(\mathrm{d})$ annealing in air to both reduce the $\mathrm{Pt}(\mathrm{acac})_{2}$ to $\mathrm{Pt}^{0}$ and oxidize and remove the PDLLA. (e) Finally, a 2 min etch in $25 \mathrm{wt} \% \mathrm{KOH}(\mathrm{aq})$ is used to selectively etch the alumina template and expose the $\mathrm{Pt}$ nanotubules. 


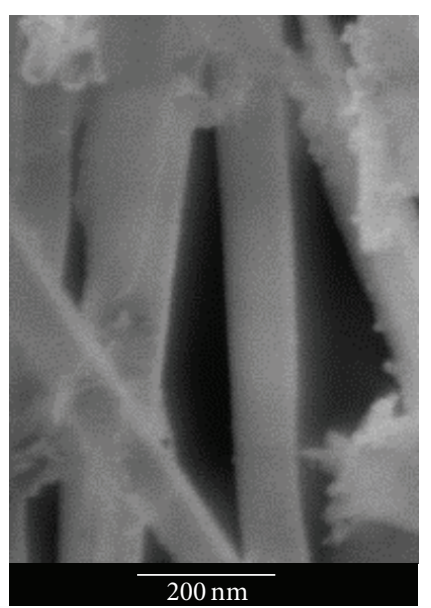

(a)

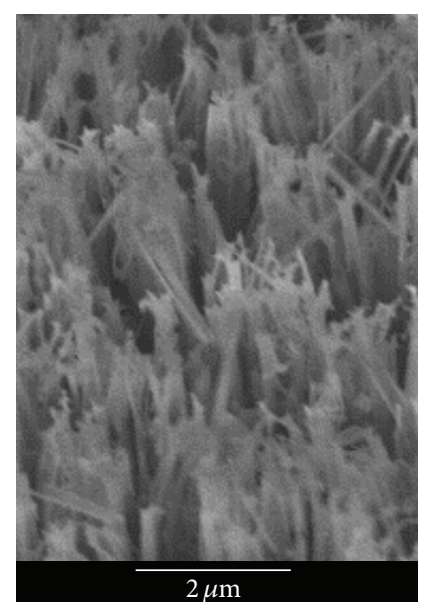

(b)

FIgURe 2: SEM images of (a) an individual $100 \mathrm{~nm}$ Pt nanotubule and (b) an array $100 \mathrm{~nm}$ Pt nanotubules.

\subsection{Electrochemical Methods. A Gamry Instruments PCI4} Potentiostat was used to perform cyclic voltammetry (CV) experiments in a traditional three-electrode cell consisting of the Pt nanotubule array, Pt disc, or Pt black working electrode described above, a platinum counter electrode, and a Ag/ $\mathrm{AgCl}$ reference electrode ( $\mathrm{CH}$ Instruments). Deaeration of solutions in the electrochemical cell was accomplished by bubbling $\mathrm{N}_{2}$ prior to experiments and maintained by subsequently blanketing the cell with $\mathrm{N}_{2}$ during the experimental procedure. Prior to analysis, the catalyst structures were electrochemically cleaned by immersing in a $0.5 \mathrm{M} \mathrm{H}_{2} \mathrm{SO}_{4}(\mathrm{aq})$ (GFS Chemicals, Veritas Grade, double distilled in $18 \mathrm{M} \Omega$ deionized water) and cycling the potential between $1.5 \mathrm{~V}$ and $0.03 \mathrm{~V}$ versus SHE (standard hydrogen electrode) at a scan rate of $500 \mathrm{mV} / \mathrm{s}$ until a steady-state voltammogram was obtained (approximately 50 cycles) [34, 35]. All potentials here are reported relative to the standard hydrogen electrode (SHE). Cyclic voltammograms collected in this same sulfuric acid solution were used to evaluate the active surface area of the platinum for each respective electrode. Integrating the hydrogen adsorption peaks with respect to time and subtracting double layer charge give the total charge due to adsorbed hydrogen [36-38]. The accepted value of $210 \mu \mathrm{C} / \mathrm{cm}^{2}$ for a monolayer of hydrogen on $\mathrm{Pt}$ was then used to calculate surface area $[36,39]$. Further characterization was then done using the standard ferrocyanide reaction in a $0.1 \mathrm{M} \mathrm{KCl}$ electrolyte solution containing $1 \mathrm{mM}$ potassium ferrocyanide (both ACS reagent grade, Sigma Aldrich).

\section{Results and Discussion}

3.1. Pt Nanotube Structure and Surface Area. Figure 2 shows scanning electron micrographs of representative $100 \mathrm{~nm} \mathrm{Pt}$ nanotubules. Tubule diameter is consistent with the template pore diameter, as shown for tubules made using the $100 \mathrm{~nm}$ pore diameter template in Figure 2(a). The high yield of the fabrication process, approximately one tubule per template

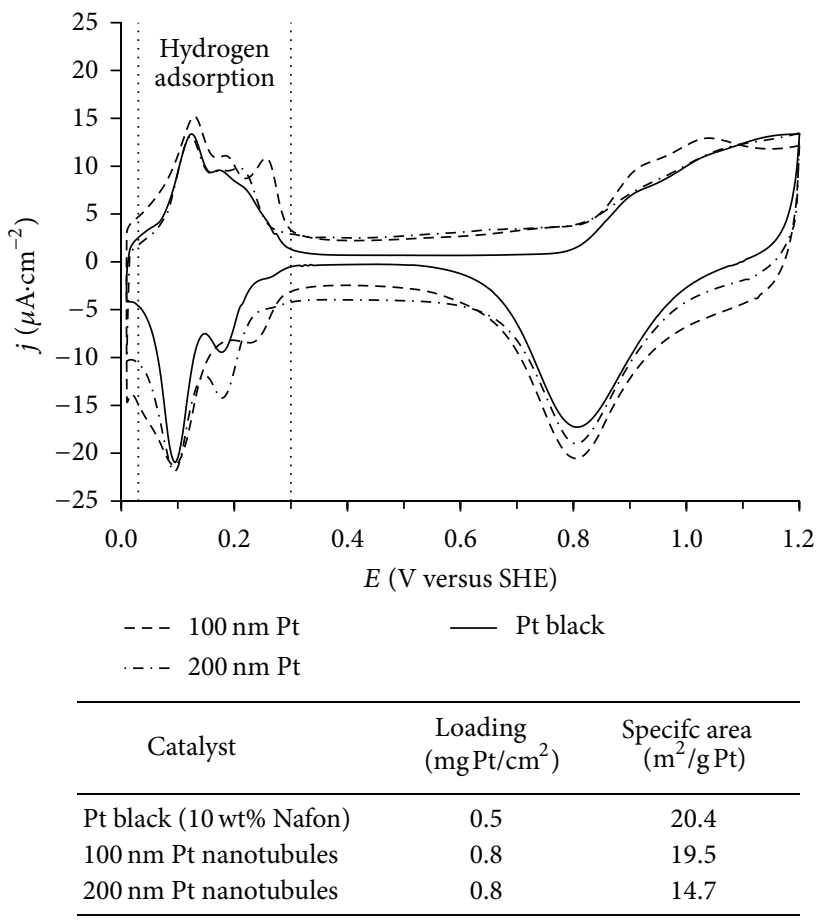

FIgURE 3: Cyclic voltammograms collected in $0.5 \mathrm{M} \mathrm{H}_{2} \mathrm{SO}_{4}(\mathrm{aq})$ at $15 \mathrm{mV} / \mathrm{s}$ of $100 \mathrm{~nm}$ and $200 \mathrm{~nm}$ Pt nanotubule electrodes and a Pt black $/ 10$ wt\% Nafion electrode. Surface areas obtained from the highlighted hydrogen adsorption region are shown in the table below the voltammograms.

pore, is readily apparent in Figure 2(b). It can also be seen that the tubule axes remain aligned with the template pore axes, normal to the flat surface of the template.

The active surface areas of platinum in electrodes made from the nanotubules, as well as for a more traditional platinum black described above, were evaluated using cyclic voltammetry in $0.5 \mathrm{M}$ sulfuric acid. Representative voltammograms are shown in Figure 3 with the hydrogen adsorption 
peaks labeled. Integration of these peaks to give the charge due to hydrogen adsorption was used to determine surface areas which are summarized in the table at the bottom of Figure 3. The active area of the nanotubule-based electrodes approached but remained somewhat lower than that of the commercial platinum black ink. In turn, the active area of the platinum black was somewhat lower than the value reported by the manufacturer (20.4 versus $27 \mathrm{~m}^{2} / \mathrm{g}$ ) due to the presence of the Nafion binder, consistent with results reported by others [40]. For the platinum disc electrode, the nominal area of the $2 \mathrm{~mm}$ diameter disc was assumed to be equivalent to the active area.

3.2. Ferrocyanide Electrochemistry. Figure 4 shows cyclic voltammograms in a $0.001 \mathrm{M}$ potassium ferrocyanide $\left(\mathrm{K}_{4} \mathrm{Fe}(\mathrm{CN})_{6}\right)$ in a $0.1 \mathrm{M} \mathrm{KCl}$ supporting electrolyte using 100 and $200 \mathrm{~nm} \mathrm{Pt}$ nanotubules and Pt black and Pt disc working electrodes at a scan rate of $10 \mathrm{mV} / \mathrm{s}$. The familiar, nearly symmetrical shape of the data curve for ferrocyanide electrooxidation-reduction is observed. Formal potentials were evaluated from the anodic and cathodic peak potentials, $E_{p, a}$ and $E_{p, c}$, respectively, according to the standard equation $E_{0}=\left(E_{p, a}+E_{p, c}\right) / 2$, [41] yielding values of $0.46 \mathrm{~V}$ versus SHE for each case (standard deviation of $0.01 \mathrm{~V}$ ). The peak current ratio $\left(i_{p, a} / i_{p, c}\right)$ was observed to be unity for all samples over the range of scan rates studied here, characteristic of an ideal reversible electron transfer reaction [41]. A plot of the anodic peak current, $i_{p, a}$, versus the square root of the scan rate, $v^{1 / 2}$, is shown in Figure 5, with the dotted lines representing a least squares fit of the data to a straight line. From the linear dependence of $i_{p, a}$ on $v^{1 / 2}$, it can be concluded that the electrode reaction is diffusion controlled.

Of particular interest is the separation between the anodic and cathodic peak potentials, $\Delta E_{p}$, which is $0.059 \mathrm{~V}$ for an ideal reversible single-electron transfer reaction [41]. For the Pt black/Nafion and Pt disc electrodes, $\Delta E_{p}$ values of 0.089 and $0.084 \mathrm{~V}$, respectively, were observed which increased slightly with scan rate to $0.105 \mathrm{~V}$ at $80 \mathrm{mV} / \mathrm{s}$. These values are typical for traditional electrodes and normally considered to represent ideal behavior for all practical purposes. The nanotubulue array electrodes, however, were observed to even more closely approach theoretically ideal behavior with $\Delta E_{p}$ values of 0.060 and $0.065 \mathrm{~V}$ for the 100 and $200 \mathrm{~nm}$ diameter nanotubule arrays, respectively, with this value being invariant over the scan rates examined.

The key kinetic parameter, the apparent heterogeneous electron transfer rate coefficient, $k_{0}$, was calculated using the method of Nicholson [41, 42], as has been commonly done for other nanostructured electrodes [21-25]. Standard values for the diffusivities of the oxidized and reduced species of $7.63 \times 10^{-6} \mathrm{~cm}^{2} / \mathrm{s}$ and $6.32 \times 10^{-6} \mathrm{~cm}^{2} / \mathrm{s}$, respectively, along with a transfer coefficient $(\alpha)$ of 0.5 were used [16]. For the polished Pt disc electrode, a value of $0.009 \mathrm{~cm} / \mathrm{s}$ for $k_{0}$ was obtained, comparable to those reported in the literature, though it should be noted that this value has been observed to be highly dependent on pretreatment and polishing methods used [16]. The Pt black/Nafion electrode yielded a somewhat smaller value of $0.003 \mathrm{~cm} / \mathrm{s}$. This is consistent with what

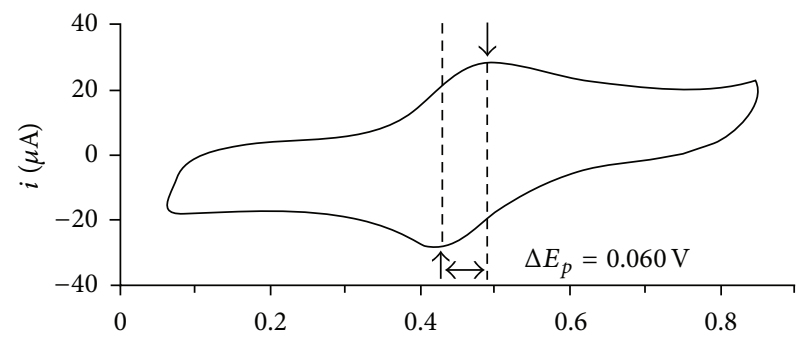

(a)

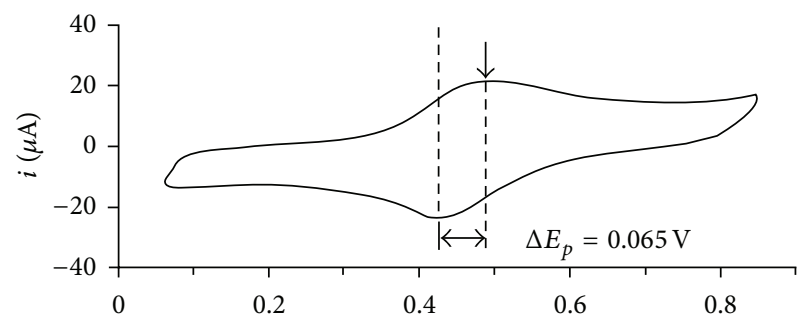

(b)

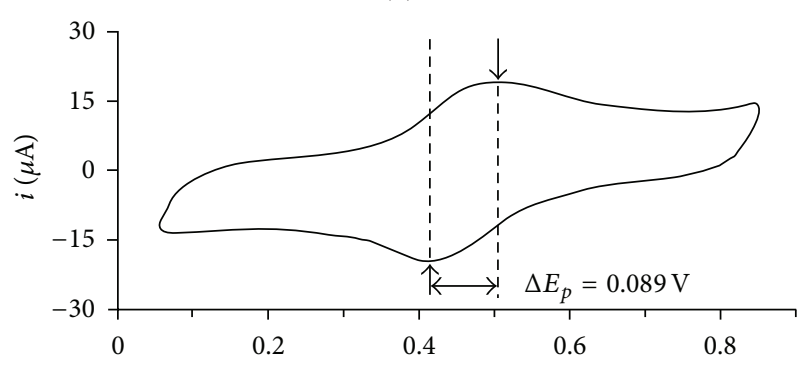

(c)

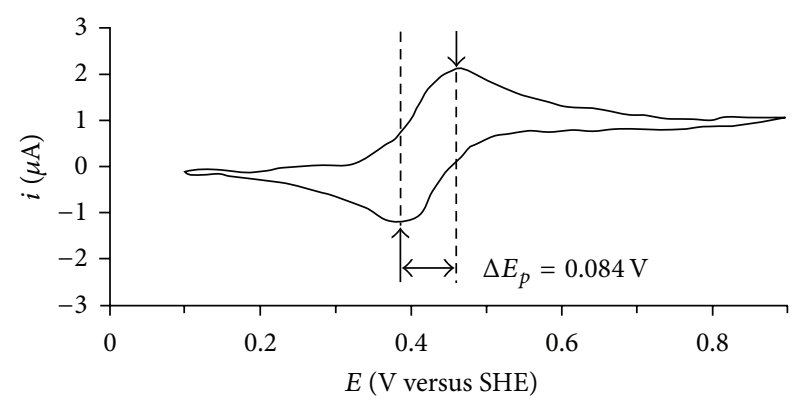

(d)

FIGURE 4: Cyclic voltammograms obtained in $0.001 \mathrm{M}$ potassium ferrocyanide $\left(\mathrm{K}_{4} \mathrm{Fe}(\mathrm{CN})_{6}\right)$ in a $0.1 \mathrm{M} \mathrm{KCl}$ supporting electrolyte at $10 \mathrm{mV} / \mathrm{s}$ with $\Delta E_{p}$ illustrated.

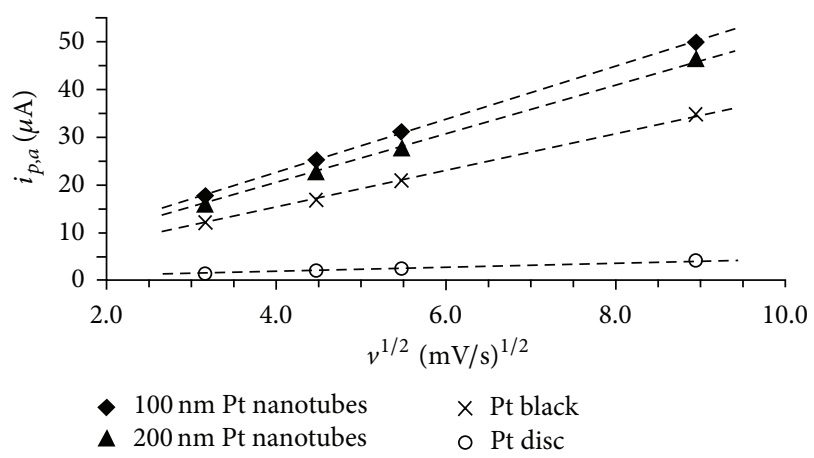

FIgURE 5: Randles-Sevcik plot of peak current versus square root of scan rate. 
would be intuitively expected as electron transfer should be impeded by both contact resistance between catalyst particles, between the catalyst and the glassy carbon, and by the presence of the Nafion binder. Significantly higher apparent electron transfer rates were observed with the nanotubulebased electrodes. Values for $k_{0}$ of 0.13 and $0.026 \mathrm{~cm} / \mathrm{s}$ for the 100 and $200 \mathrm{~nm}$ diameter nanotubule arrays, respectively, were obtained, one to two orders of magnitude greater than observed with the more traditional electrode structures. Similar trends have been reported when comparing carbon nanotube electrode structures to more traditional carbon electrodes (e.g., glassy carbon, carbon pasted, etc.) [21-25]. In carbon, this trend has been attributed to some unique catalytic effect of the carbon nanotubes themselves [24,25]. Similar trends have also been reported for platinum nanowire arrays with regard to the heterogeneous electron transfer coefficient, though for the electrooxidation of methanol [2, $3,9,12,35]$.

Similar trends have been reported when comparing carbon nanotube- [21-25] or platinum nanowire- [2, 3, 9, 12, 35] based electrodes to traditional glassy carbon, platinum disc, or other standard electrodes. As noted previously, however, studies of Pt nanostructures have focused on methanol and other organic molecules. Many have attributed these results in carbon nanotubes to some unique catalytic effect of the carbon [24, 25] or platinum nanostructures [2, 9, 12, 35] themselves. This conclusion has commonly been based on an increased heterogeneous electron transfer coefficient, as observed here. However, the Nicholson method used in calculating $k_{0}$ assumes semi-infinite diffusion to the electrode surface, which is the case for flat disc electrodes and microelectrodes, but not necessarily for a nanotubule array as studied in this work (or carbon nanotube carpets, platinum nanowire arrays, and other similar structures). Streeter et al. proposed a thin film model for a similar nanoarray electrode structure [43]; however, this model neglects bulk diffusion to the top of the nanoarray. Semi-infinite diffusion would be expected from the bulk electrolyte to the top of the nanoarray structure, while something akin to diffusion in porous media might be expected in the spaces between the nanotubules in the array. The Nicholson method remains valuable for comparing various electrodes; however, due to the aforementioned limitations with nanoarrays, we refer to the heterogeneous electron transfer coefficient as an "apparent" value in this work. The increased $k_{0}$ values observed with the platinum nanotubules arrays here may still be due to a catalytic effect, as has been suggested with other nanostructures, and/or due to an apparent mass transfer enhancement. The RandlesSevcik model derived for semi-infinite diffusion to a flat surface where an ideally completely reversible reaction occurs predicts that the slope of a plot of $i_{p, a}$ versus $\nu^{1 / 2}$ will be proportional to the diffusivity of the reacting species [41]. As seen in Figure 5, the slope of the $i_{p, a}$ versus $\nu^{1 / 2}$ fit lines is significantly greater for the nanotubule array electrodes, indicative of an increase in the apparent diffusivity for the ferro/ferricyanide ions as compared to the platinum black/ Nafion and platinum disc electrodes.

\section{Conclusions}

Template wetting nanofabrication was used to prepare $\mathrm{Pt}$ nanotubular catalyst structures in a porous alumina membrane. The resulting high surface area Pt nanostructures were characterized electrochemically using the ferro/ferricyanide reaction. Though common with both $\mathrm{Pt}$ and carbon electrodes, especially carbon nanotube electrodes, this standard reaction has not previously been used to characterize nanostructured Pt electrodes. The nanotubule electrodes more closely approached ideal, reversible behavior and exhibited a one to two order of magnitude greater apparent heterogeneous electron transfer coefficient than standard platinum disc and platinum black electrodes. While the source of this improvement is not clear at this time, this nanoarray structure shows promise for sensor or small fuel cell applications.

\section{Conflict of Interests}

The authors have of this paper do not have any direct financial relation with the commercial identities mentioned in this paper that might lead to a conflict of interests.

\section{Acknowledgments}

This work was funded in part by the Louisiana Board of Regents/RCS Program, Award LEQSF (2006-09)-RD-A-21.

\section{References}

[1] M. H. Yang, F. L. Qu, Y. S. Lu, Y. He, G. L. Shen, and R. Q. Yu, "Platinum nanowire nanoelectrode array for the fabrication of biosensors," Biomaterials, vol. 27, no. 35, pp. 5944-5950, 2006.

[2] S. M. Choi, J. H. Kim, J. Y. Jung, E. Y. Yoon, and W. B. Kim, "Pt nanowires prepared via a polymer template method: its promise toward high Pt-loaded electrocatalysts for methanol oxidation," Electrochimica Acta, vol. 53, no. 19, pp. 5804-5811, 2008.

[3] X. Y. Zhang, W. Lu, J. Y. Da, H. T. Wang, D. Y. Zhao, and P. A. Webley, "Porous platinum nanowire arrays for direct ethanol fuel cell applications," Chemical Communications, no. 2, pp. 195197, 2009.

[4] M. Steinhart, J. H. Wendorff, and R. B. Wehrspohn, "Nanotubes à la carte: wetting of porous templates," ChemPhysChem, vol. 4, no. 11, pp. 1171-1176, 2003.

[5] Y. Luo, S. K. Lee, H. Hofmeister, M. Steinhart, and U. Gösele, "Pt nanoshell tubes by template wetting," Nano Letters, vol. 4, no. 1, pp. 143-147, 2004.

[6] Y. Piao, H. Lim, J. Y. Chang, W.-Y. Lee, and H. Kim, "Nanostructured materials prepared by use of ordered porous alumina membranes," Electrochimica Acta, vol. 50, no. 15, pp. 2997-3013, 2005.

[7] Y.-J. Song, S.-B. Han, and K.-W. Park, "Pt nanowire electrodes electrodeposited in PVP for methanol electrooxidation," Materials Letters, vol. 64, no. 18, pp. 1981-1984, 2010.

[8] W. C. Choi and S. I. Woo, "Bimetallic Pt-Ru nanowire network for anode material in a direct-methanol fuel cell," Journal of Power Sources, vol. 124, no. 2, pp. 420-425, 2003.

[9] J. M. Kim, H.-I. Joh, S. M. Jo et al., "Preparation and characterization of Pt nanowire by electrospinning method for methanol 
oxidation," Electrochimica Acta, vol. 55, no. 16, pp. 4827-4835, 2010.

[10] X. S. He, C. G. Hu, and H. Liu, "Fabrication of 3D Pt catalysts via support of $\mathrm{Na}_{2} \mathrm{Ti}_{3} \mathrm{O}_{7}$ nanowires for methanol and ethanol electrooxidation," Catalysis Communications, vol. 12, p. 100, 2010.

[11] L. Su, W. Z. Jia, A. Schempf, and Y. Lei, "Palladium/titanium dioxide nanofibers for glycerol electrooxidation in alkaline medium," Electrochemistry Communications, vol. 11, no. 11, pp. 2199-2202, 2009.

[12] S. H. Sun, G. X. Zhang, D. S. Geng et al., "Direct growth of single-crystal Pt nanowires on Sn@CNT nanocable: 3D electrodes for highly active electrocatalysts," Chemistry, vol. 16, no. 3, pp. 829-835, 2010.

[13] Z. X. Liang, J. Y. Shi, S. J. Liao, and J. H. Zeng, "Noble metal nanowires incorporated Nafion membranes for reduction of methanol crossover in direct methanol fuel cells," International Journal of Hydrogen Energy, vol. 35, no. 17, pp. 9182-9185, 2010.

[14] I.-S. Park, J.-H. Choi, and Y.-E. Sung, "Synthesis of $3 \mathrm{~nm} \mathrm{Pt}$ nanowire using MCM-41 and electrocatalytic activity in methanol electro-oxidation," Electrochemical and Solid-State Letters, vol. 11, no. 5, pp. B71-B75, 2008.

[15] S. Y. Wang, X. Wang, and S. P. Jiang, "Controllable self-assembly of Pd nanowire networks as highly active electrocatalysts for direct formic acid fuel cells," Nanotechnology, vol. 19, 2008.

[16] R. L. McCreery, "Carbon electrodes: structural effects on electron transfer kinetics," in Electroanalytical Chemistry: A Series of Advances, A. J. Bard, Ed., vol. 17, p. 221, Marcel Dekker, New York, NY, USA, 1991.

[17] E. L. Goldstein and M. R. Vandemark, "Electrode cleaning and anion effects on $k_{s}$ for $\mathrm{K}_{3} \mathrm{Fe}(\mathrm{CN})_{6}$ couple," Electrochimica Acta, vol. 27, pp. 1079-1085, 1982.

[18] W. H. Huang and R. McCreery, "Electron transfer kinetics of $\mathrm{Fe}(\mathrm{CN}) 6$ 3- 4- on laser-activated and $\mathrm{CN}$-modified Pt electrodes," Journal of Electroanalytical Chemistry, vol. 326, no. 1-2, pp. 1-12, 1992.

[19] C. Beriet and D. Pletcher, "A microelectrode study of the mechanism and kinetics of the ferro/ferricyanide couple in aqueous media: the influence of the electrolyte and its concentration," Journal of Electroanalytical Chemistry, vol. 361, no. 1-2, pp. 93101, 1993.

[20] K. Winkler, "The kinetics of electron transfer in $\mathrm{Fe}(\mathrm{CN}) 6$ 43- redox system on platinum standard-size and ultramicroelectrodes," Journal of Electroanalytical Chemistry, vol. 388, no. 1-2, pp. 151-159, 1995.

[21] R. R. Moore, C. E. Banks, and R. G. Compton, "Basal plane pyrolytic graphite modified electrodes: comparison of carbon nanotubes and graphite powder as electrocatalysts," Analytical Chemistry, vol. 76, no. 10, pp. 2677-2682, 2004.

[22] D. Salinas-Torres, F. Huerta, F. Montilla, and E. Morallón, "Study on electroactive and electrocatalytic surfaces of single walled carbon nanotube-modified electrodes," Electrochimica Acta, vol. 56, no. 5, pp. 2464-2470, 2011.

[23] P. Szroeder, N. G. Tsierkezos, P. Scharff, and U. Ritter, "Electrocatalytic properties of carbon nanotube carpets grown on $\mathrm{Si}$ wafers," Carbon, vol. 48, no. 15, pp. 4489-4496, 2010.

[24] I. Dumitrescu, P. R. Unwin, and J. V. MacPherson, "Electrochemistry at carbon nanotubes: perspective and issues," Chemical Communications, no. 45, pp. 6886-6901, 2009.
[25] J. M. Nugent, K. S. V. Santhanam, A. Rubio, and P. M. Ajayan, "Fast electron transfer kinetics on multiwalled carbon nanotube microbundle electrodes," Nano Letters, vol. 1, no. 2, pp. 87-91, 2001.

[26] G. Y. Zhao, C. L. Xu, D. J. Guo, H. Li, and H. L. Li, “Template preparation of $\mathrm{Pt}-\mathrm{Ru}$ and $\mathrm{Pt}$ nanowire array electrodes on a Ti/ Si substrate for methanol electro-oxidation," Journal of Power Sources, vol. 162, pp. 492-496, 2006.

[27] Y. Bai, Y. Sun, and C. Sun, "Pt-Pb nanowire array electrode for enzyme-free glucose detection," Biosensors and Bioelectronics, vol. 24, no. 4, pp. 579-585, 2008.

[28] K. S. Napolskii, P. J. Barczuk, S. Y. Vassiliev, A. G. Veresov, G. A. Tsirlina, and P. J. Kulesza, "Templating of electrodeposited platinum group metals as a tool to control catalytic activity," Electrochimica Acta, vol. 52, no. 28, pp. 7910-7919, 2007.

[29] B. Krishnamurthy, S. Deepalochani, and K. S. Dhathathreyan, "Effect of ionomer content in anode and cathode catalyst layers on direct methanol fuel cell performance," Fuel Cells, vol. 8, no. 6, pp. 404-409, 2008.

[30] S. Litster and G. McLean, "PEM fuel cell electrodes," Journal of Power Sources, vol. 130, no. 1-2, pp. 61-76, 2004.

[31] E. Passalacqua, F. Lufrano, G. Squadrito, A. Patti, and L. Giorgi, "Nafion content in the catalyst layer of polymer electrolyte fuel cells: Effects on structure and performance," Electrochimica Acta, vol. 46, no. 6, pp. 799-805, 2001.

[32] G. Sasikumar, J. W. Ihm, and H. Ryu, "Optimum Nafion content in PEM fuel cell electrodes," Electrochimica Acta, vol. 50, no. 2-3, pp. 601-605, 2004.

[33] Y. M. Zhu, S. Y. Ha, and R. I. Masel, "High power density direct formic acid fuel cells," Journal of Power Sources, vol. 130, no. 1-2, pp. 8-14, 2004.

[34] S. L. Gojković and T. R. Vidaković, "Methanol oxidation on an ink type electrode using Pt supported on high area carbons," Electrochimica Acta, vol. 47, pp. 633-642, 2001.

[35] Y. Zhong, C.-L. Xu, L.-B. Kong, and H.-L. Li, "Synthesis and high catalytic properties of mesoporous Pt nanowire array by novel conjunct template method," Applied Surface Science, vol. 255, no. 5, pp. 3388-3393, 2008.

[36] S. Gomez, L. Erades, K. Philippot et al., "Platinum colloids stabilized by bifunctional ligands: self-organization and connection to gold," Chemical Communications, no. 16, pp. 1474-1475, 2001.

[37] M. Shabrang, H. Mizota, and S. Bruckenstein, "Adatom coverage dependences and specificity effects on the rate of formic acid electro-oxidation at polycrystalline platinum," Journal of the Electrochemical Society, vol. 131, no. 2, pp. 306-314, 1984.

[38] D. T. Sawyer, A. Sobkowiak, J. Julian, and L. Roberts, Electrochemistry For Chemists, John Wiley \& Sons, New York, NY, USA, 1995.

[39] A. M. Feltham and M. Spiro, "Platinized platinum electrodes," Chemical Reviews, vol. 71, no. 2, pp. 177-193, 1971.

[40] M. S. McGovern, E. C. Garnett, C. Rice, R. I. Masel, and A. Wieckowski, "Effects of Nafion as a binding agent for unsupported nanoparticle catalysts," Journal of Power Sources, vol. 115, no. 1, pp. 35-39, 2003.

[41] A. J. Bard and L. R. Faulkner, Electrochemical Methods: Fundamentals and Applications, John Wiley \& Sons, Hoboken, NJ, USA, 2001.

[42] R. S. Nicholson, "Theory and application of cyclic voltammetry for measurement of electrode reaction kinetics," Analytical Chemistry, vol. 37, no. 11, pp. 1351-1355, 1965. 
[43] I. Streeter, G. G. Wildgoose, L. Shao, and R. G. Compton, "Cyclic voltammetry on electrode surfaces covered with porous layers: an analysis of electron transfer kinetics at single-walled carbon nanotube modified electrodes," Sensors and Actuators B, vol. 133, no. 2, pp. 462-466, 2008. 

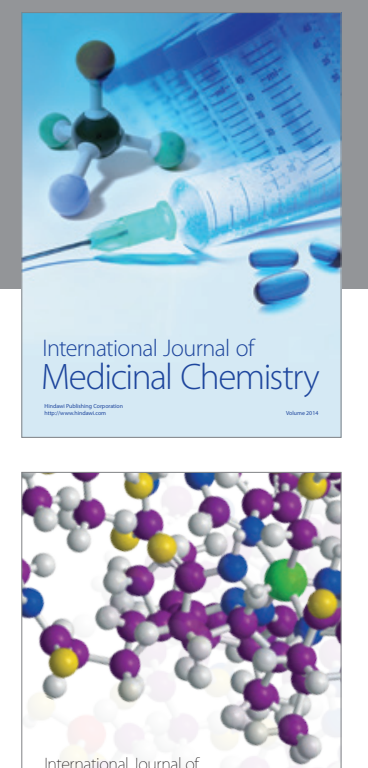

\section{Carbohydrate} Chemistry

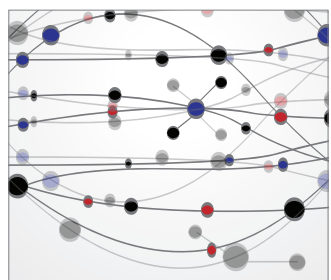

The Scientific World Journal
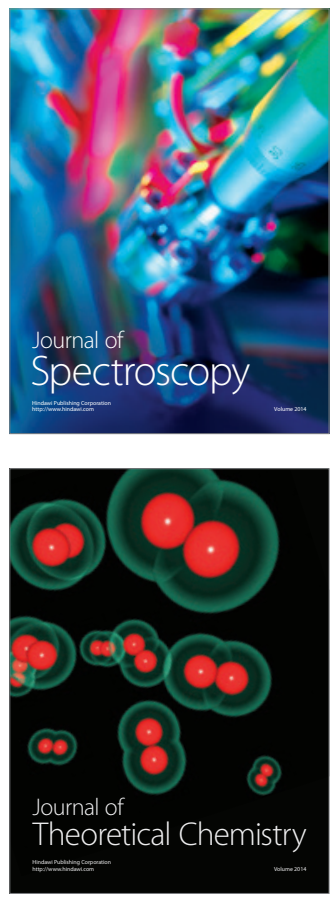
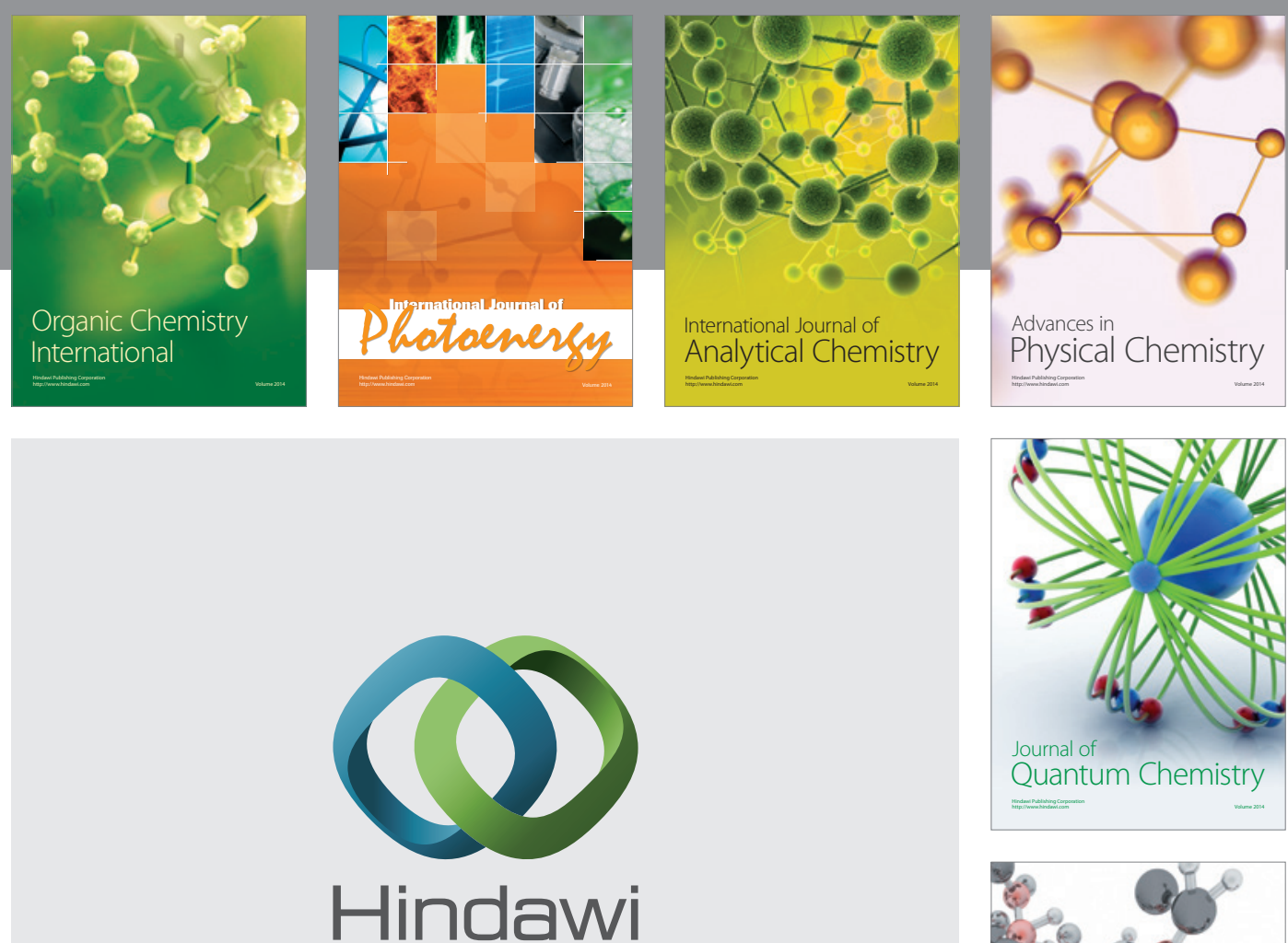

Submit your manuscripts at

http://www.hindawi.com

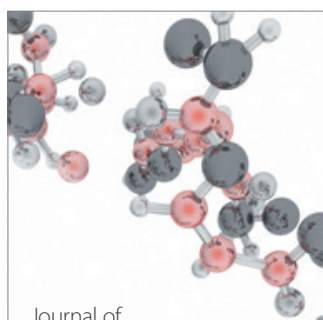

Analytical Methods

in Chemistry

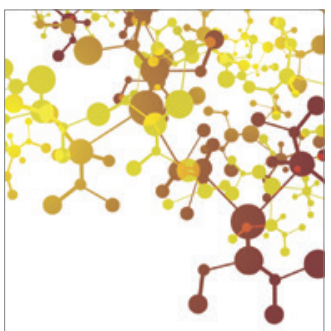

Journal of

Applied Chemistry

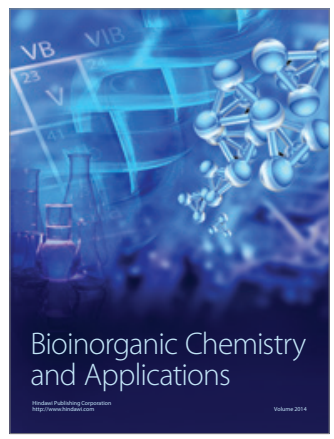

Inorganic Chemistry
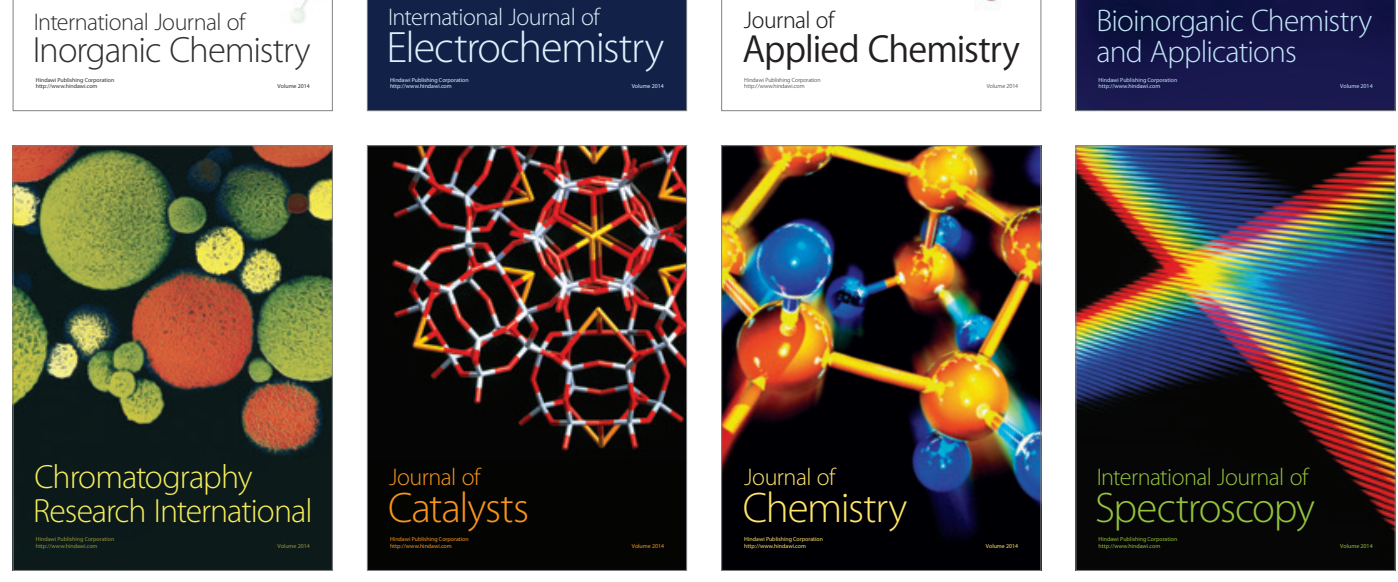